\title{
Feeding and Food Consumption by the Barents Sea Skates
}

\author{
A.V. Dolgov \\ Polar Research Institute of Marine Fisheries and Oceanography (PINRO) \\ 6 Knipovich Street, 183763, Murmansk, Russia
}

\begin{abstract}
Dolgov, A. V. 2005. Feeding and Food Consumption by the Barents Sea Skates. J. Northw. Atl. Fish. Sci., 35: 495-503. doi:10.2960/J.v35.m523
\end{abstract}

\begin{abstract}
Stomach contents data were used to investigate spatial, seasonal and inter-annual patterns of feeding of the thorny skate (Amblyraja radiata) in the Barents Sea during 1994-2000. The diets and food consumption by the thorny skate of different size groups were analyzed and assessed with special reference to the consumption of commercial species of fishes and crustaceans. Less comprehensive data on food composition are presented for other less abundant Barents Sea skates: arctic skate ( $A$. hyperborea), round skate (Rajella fyllae), blue skate (Dipturus batis), spinytail skate (Bathyraja spinicauda) and sail ray (D. linteus).
\end{abstract}

Key words: Barents Sea, diet, feeding, length, predation, skates

\section{Introduction}

The Barents Sea is inhabited by eight skate species: thorny skate (Amblyraja radiata), arctic skate (A. hyperborea), round skate (Rajella fyllae), blue skate (Dipturus batis), spinytail skate (Bathyraja spinicauda), sail ray (D. linteus), long-nosed skate (D. oxyrhynchus) and shagreen ray (Leucoraja fullonica) (Andriyashev, 1954; Dolgov, MS 2000a). Despite the regular bycatch of skates by demersal fisheries, there are no extensive fisheries for skates in the Barents Sea (Dolgov et al., 2004b). This has resulted in the biology and feeding of most of these species to remain largely unknown. Feeding has been studied for only the thorny and round skate (Zenkevich and Brotskaya, 1931; Antipova and Nikiforova, MS 1983; Berestovsky, 1989; Dolgov, MS 1997); feeding information is limited for all other skate species in the Barents Sea.

The present study investigates feeding of the six skate species reported from scientific and commercial catches in the Barents Sea during the period 1994-2000. The purpose of the study is to describe their diets and estimate the effects of their predation on commercial stocks of fishes and crustaceans from analysis of stomach contents.

\section{Materials and Methods}

Skate stomachs were collected aboard both research and commercial vessels. Some stomachs with their contents were frozen for subsequent analysis in the laboratory, whereas the stomach contents of most were analyzed at sea. The number, total length (TL) and mass of each prey species occurring in skate stomachs were identified and various biological variables were recorded from the predator (TL, mass, sex and stomach fullness). TL for shrimps was measured from the postorbital hollow to the distal end of the telson. Prey items were classified to the lowest identifiable taxon. Digestive tracts, gonads and other viscera of fish found separate from other fish remains among the stomach contents of the skates were classed as 'fisheries waste'. Fisheries waste was readily distinguished from digested fish, which occurred as whole fish or as heads, skeletons or other parts.

The stomach contents from 2192 thorny skates, 85 round skates, 48 arctic skates, 39 blue skates, 14 spinytail skates and 5 sail rays were examined and then summarised for each species separately. Percentage by mass $(\mathrm{m})(\%$ of the stomach contents mass) and frequency of occurrence (f) (\% of feeding fish) were used as feeding indices. Stomach fullness was visually determined using a fivepoint scale: 0 , empty; 1 , low fullness; 2 , mean fullness; 3 , full stomach; and 4, full stomach with walls stretched by food. An index of fullness was calculated as the stomach contents mass divided by the fish mass and multiplied by 10000 . The length-frequency distribution of each prey species was evaluated as a percentage of the total number of measured specimens in the stomachs.

Food consumption by thorny skate in the entire Barents Sea was calculated within $5 \mathrm{~cm}$ TL-groups and summed for the seasonal quarters January-March, April-June, July-September, and October-December. Daily rations for all TL-groups in all quarters was taken as $0.80 \%$ of the body mass (Berestovsky, 1989). The abundance index for each TL-group was calculated as the mean number of skates per trawl tow based on survey data for 1994-2000, assuming constant abundance between seasons and years (Dolgov, MS 1997; Dolgov et al., 2004a). Approximate consumption by other skates was 
calculated using averaged data on food composition and mean total stock biomass for period 1998-2000 (Dolgov et al., 2004a). Mean daily food consumption was taken as $1 \%$ of the body mass of skates.

\section{Results}

\section{Food composition}

Thorny skate stomach contents consisted primarily of fish and large crustaceans (shrimps and crabs) (Table 1). Of more than 18 species of fish identified, young cod (Gadus morhua) (12\% by mass) and capelin (Mallotus villosus) ( $6 \%$ by mass) were the most prevalent. Demersal crustaceans were represented mainly by northern shrimp (Pandalus borealis) (9\% by mass). Fisheries waste, which was an important component in the diet of the skates, occurred in $12 \%$ of stomachs and was $35 \%$ of the mass of stomach contents. The importance of small food items (Gammaridea, Euphausiidae and Polychaeta) reduced with increasing length of skate, whereas the importance of large crustaceans and fish increased (Fig. 1). The diet of skates in the 31-35 cm TL-group and larger consisted mainly of fish and large decapods. There was no observed regularity in the seasonal pattern of food composition of thorny skate during 1994-2000 (Fig. 2).

Round skate fed mainly on bottom benthos (Table 1), especially Polychaeta (31\% by mass) and Gammaridae (14\% by mass). Northern shrimp ( $26 \%$ by mass) and fisheries waste ( $10 \%$ by mass) were also major components of their diets. Fish (mostly capelin and young cod) occurred in small quantities. Small individuals $(<35 \mathrm{~cm}$ TL) consumed exclusively benthos (Polychaeta and Gammaridae) and only those of the 36-40 cm TL-group and larger fed on bigger prey (Fig. 3). The largest skates (51-55 cm TL-group) had a high proportion of small benthic organisms $(<30-40 \%)$.

Arctic skate stomach contents consisted mainly of fish ( $\sim 90 \%$ by mass) (Table 1$)$, including herring (Clupea harengus), capelin and redfish (Sebastes spp). The portion of northern shrimp was also comparatively high ( $8.3 \%$ by mass), whereas that of fisheries waste did not exceed $2 \%$.

Blue skate stomach contents consisted largely of fish ( $\sim 70 \%$ by mass), with young cod and haddock (Melanogrammus aeglefinus), redfish and long rough dab (Hippoglossoides platessoides limandoides) prevalent (Table 1). One of the stomachs contained a young round skate of $17 \mathrm{~cm} \mathrm{TL}$. Fisheries waste was another important food source ( $25 \%$ by mass).
Spinytail skate stomach contents were dominated by fish ( $90 \%$ by mass) (Table 1$)$, which included haddock, redfish and long rough dab. One of the stomachs contained a round skate of $26 \mathrm{~cm}$ TL.

Sail ray data on stomach contents were very sparse (Table 1). In the stomachs of two young individuals of 22-28 cm TL caught on the Fugløy Bank (mean fullness indices of 28.1-62.2\% $\%$ ) only Gammaridea were found. Food composition of larger individuals was more varied. The stomach of a $72 \mathrm{~cm}$ TL male (mean fullness index of $140.0 \%$ \% caught at the Nordkyn Bank contained 9 northern shrimp of 2.5-11 cm TL, 4 Sabinea septemcarinata of 4-6 cm TL, 1 Munida sp. of $2.5 \mathrm{~cm}$ carapace length, and the remnants of Ophiura spp. The stomach of a $94 \mathrm{~cm}$ female (fullness index of $661.6 \%$ ) caught in the same area contained mainly fisheries waste. Additionally, it contained one northern shrimp of $10 \mathrm{~cm}$ TL, and one Norway pout (Trisopterus esmarkii) of $18 \mathrm{~cm}$ TL.

\section{Length composition of prey}

The length of consumed prey depended on predator length. The length of small-sized prey, particularly northern shrimp ranging $1-13 \mathrm{~cm}$ TL was similar in the stomachs of most skate species (Fig. 4). Despite the small number of measured shrimp specimens in skate stomachs (excluding thorny skate), the dominance of $7-10 \mathrm{~cm}$ length shrimp was observed. The same was noted in small-sized fish, e.g. capelin in the stomachs ranged 6-17 cm TL for all skate species reaching the 16-20 cm TL-group. In larger-sized fish, size-selective consumption was observed in different skate species. The maximum length of young cod and redfish in the stomachs of thorny skate did not exceed 29 and $21 \mathrm{~cm}$ TL, respectively, whereas in blue skate, their lengths reached 40 and $25 \mathrm{~cm} \mathrm{TL}$, respectively (Fig. 5-6). The length of long rough dab in the stomachs of thorny skate did not exceed $19 \mathrm{~cm}$ TL (Fig. 7), but reached $35 \mathrm{~cm}$ TL in those of blue skate.

\section{Food consumption}

Mean annual biomass of food consumed by thorny skate during 1994-2000 was calculated at 165.7 tons, of which 73.7 thousand tons comprised commercial fishes and invertebrates (Table 2). The major items of food were northern shrimp and cod at 31.8 and 16.4 thousand tons, respectively. Estimated consumption by other skates was much lower and ranged from 2.2 thousand tons for spinytail skate to 12.7 thousand tons for arctic skate. (Table 3). Total food consumption by all skate species (except thorny skate) was 31.4 thousand tons, of which 18.2 thousand tons comprised commercial species. 


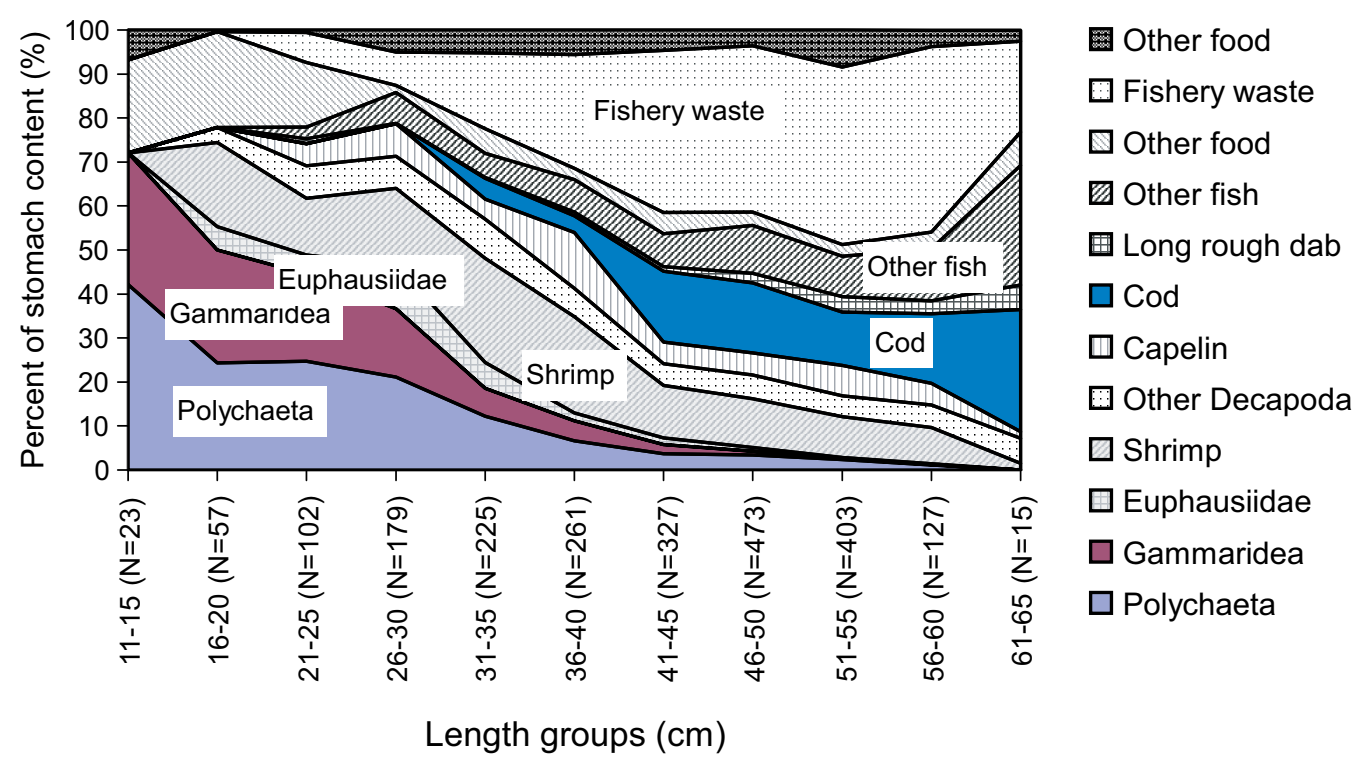

Fig. 1. Variation in composition of stomach contents with total length of thorny skate.

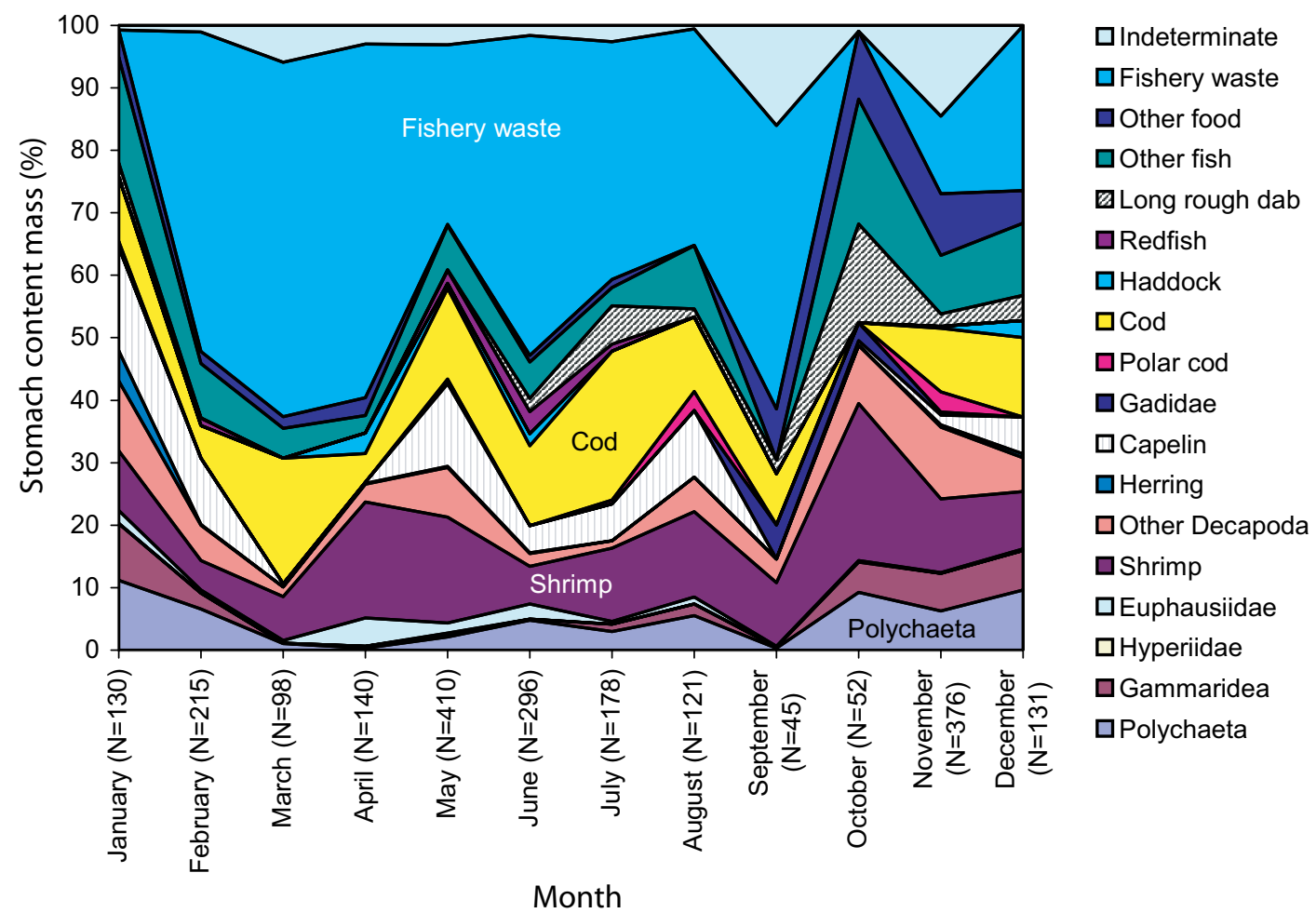

Fig. 2. Variation in composition of stomach contents with month for thorny skate. 


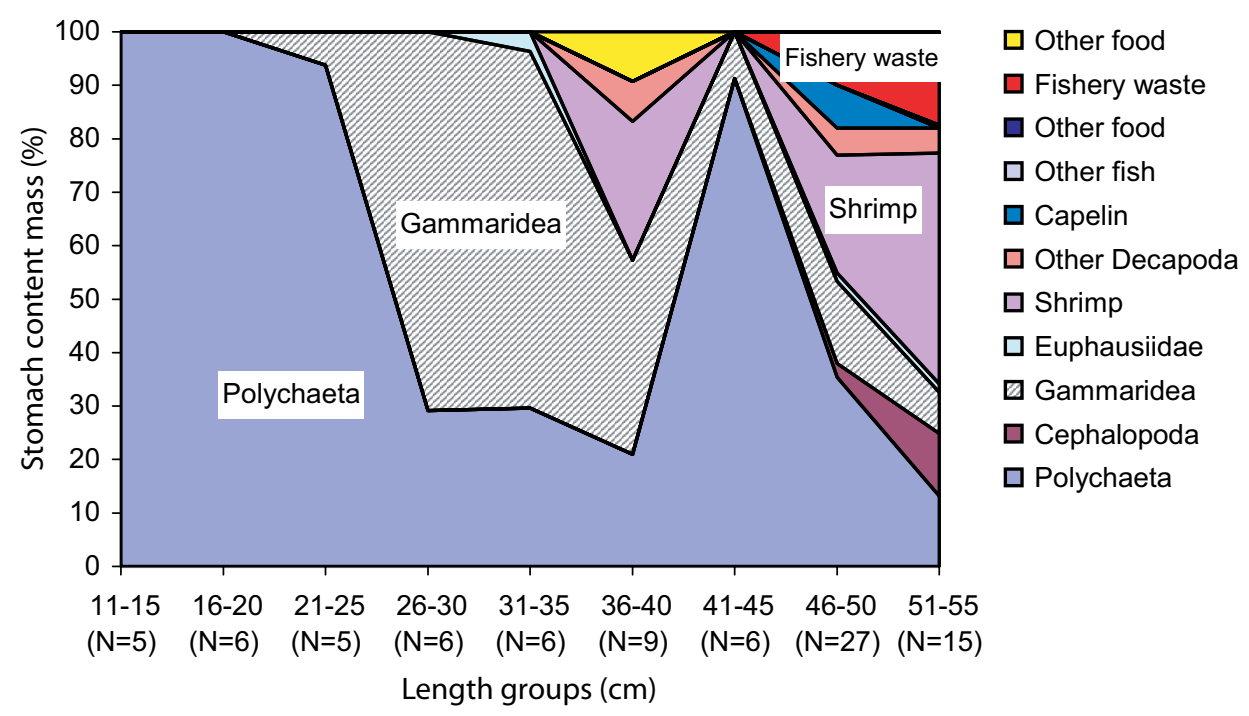

Fig. 3. Variation in composition of stomach contents with length of round skate.
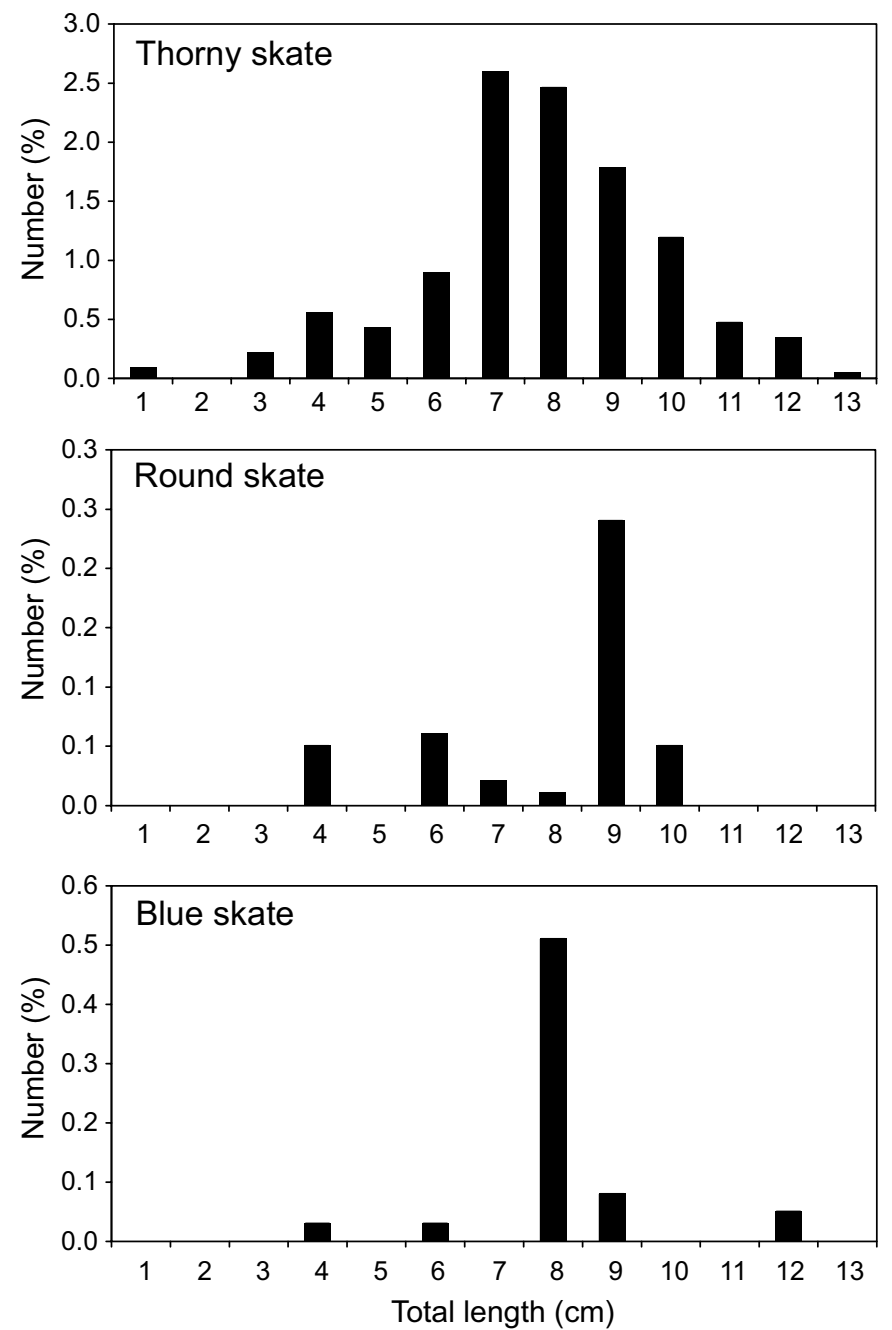

Fig. 4. Length distribution of northern shrimp in the stomachs of skates. 
DOLGOV: Feeding by Barents Sea Skates

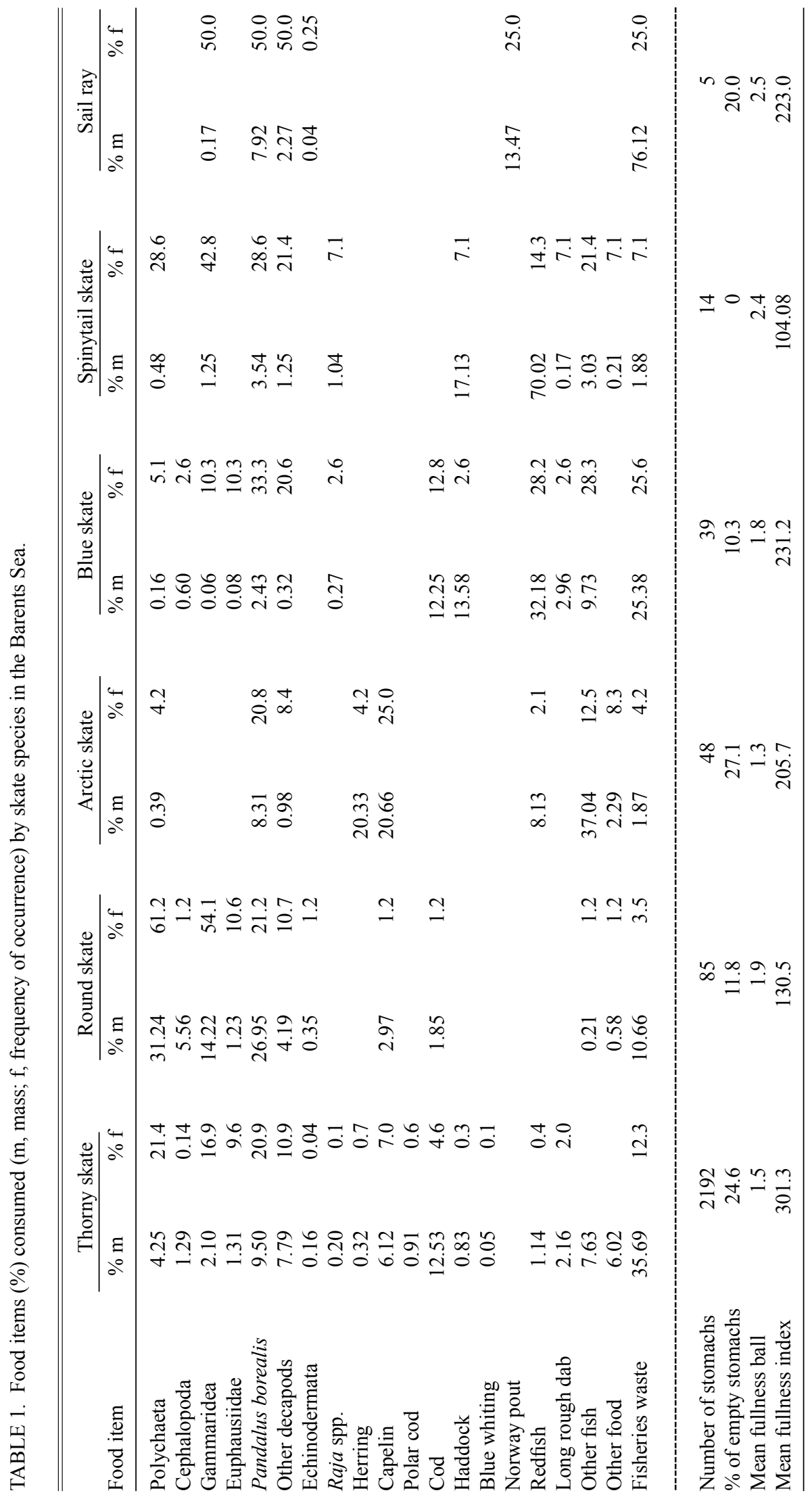



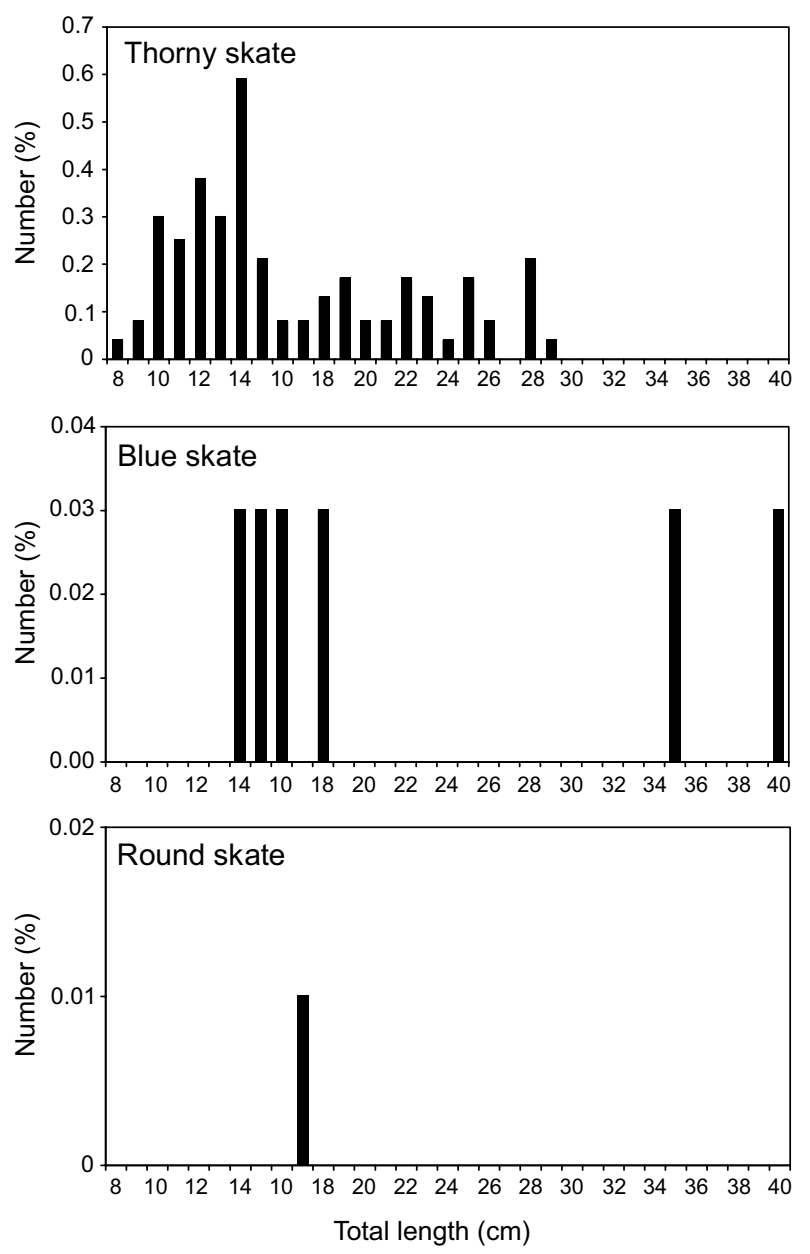

Fig. 5. Length distribution of cod in the stomachs of skates.

\section{Discussion}

Information on food composition and prey size for thorny skate stomachs obtained by the present study agrees with those obtained from previous studies. This applies to studies both in the Barents Sea (Zenkevich and Brotskaya, 1931; Antipova and Nikiforova, 1983; Berestovsky, 1989) and in the rest of the North Atlantic (Templeman, 1982; Pedersen, 1995; Bjelland et al., 2000; Skjæraasen and Bergstad, 2000). Young thorny skates are considered typical benthos-feeders, whereas larger ones feed on various decapods and fishes. Round skate, which is also considered a typical benthos-feeder (Berestovsky, 1989), can feed on young cod and capelin. Other skates are largely piscivorous species, which is confirmed by a few data from other North Atlantic areas (Andriyashev, 1954; Stehmann and Bürkel, 1984; Bjelland et al., 2000). Scarcity of data prevents any conclusions about the diet of the sail ray. Many skate species in the Barents Sea feed actively on fisheries waste. This may suggest a deficiency in the natural food supply, but is more likely to reflect the availability of fisheries waste as an additional source of food.

Most predation by skates in the Barents Sea is by the thorny skate, which makes up $95.8 \%$ of the abundance and $91.8 \%$ of the biomass of the Barents Sea skates (Dolgov et al., 2004a). The total biomass of commercial species consumed by skates is high ( $>90$ thousand tons), but the biomass of each particular species is not high, with the exception of northern shrimp and young cod. Hence, the total capelin biomass consumed by skates (16.9 thousand tons) is much less than both the mean capelin stock and catch of 1692.0 and 135.0 thousand tons, respectively, during the period 1994-2001 (Anon., 2002a). However, estimated consumption of northern shrimp by skates (34.7 thousand 

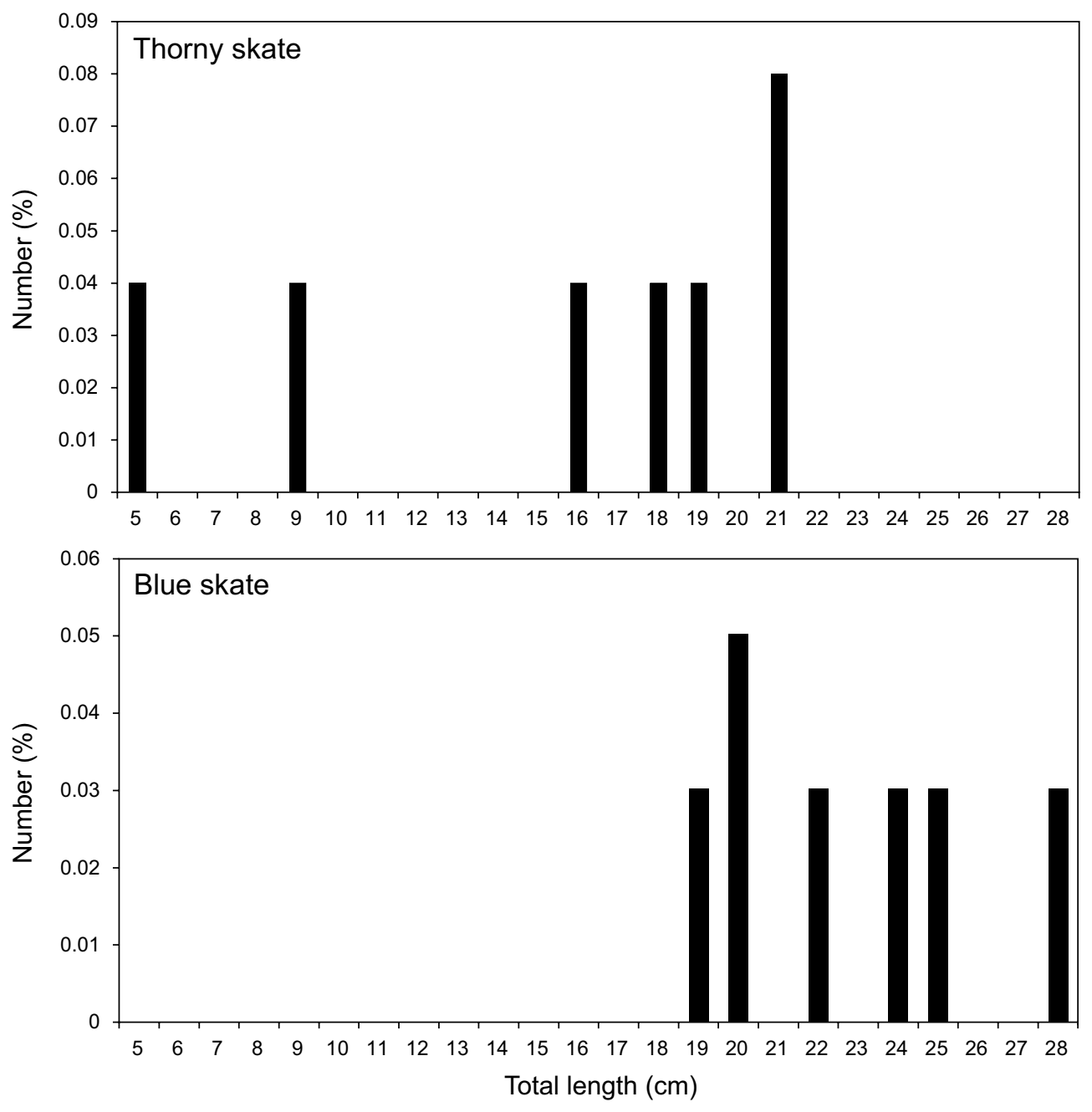

Fig. 6. Length distribution of redfish in the stomachs of skates.

tons) is similar to the shrimp catch (49.0 thousand tons), which represents $8 \%$ of the total northern shrimp stock biomass (Anon., 2002b). The total biomass of food consumed by skates, compared with consumption by the most abundant fishes in Barents Sea, is not high. It does not exceed $5-7 \%$ of consumption by cod, but it is very close to the food consumption by species such as Greenland halibut (Reinhardtius hippoglossoides) and long rough dab (Dolgov, 1999; Dolgov, 2000b). Nevertheless, it should be noted that skates feed largely on young fish and their predation may have some impact on the recruitment to commercial stocks of fish and invertebrates. 

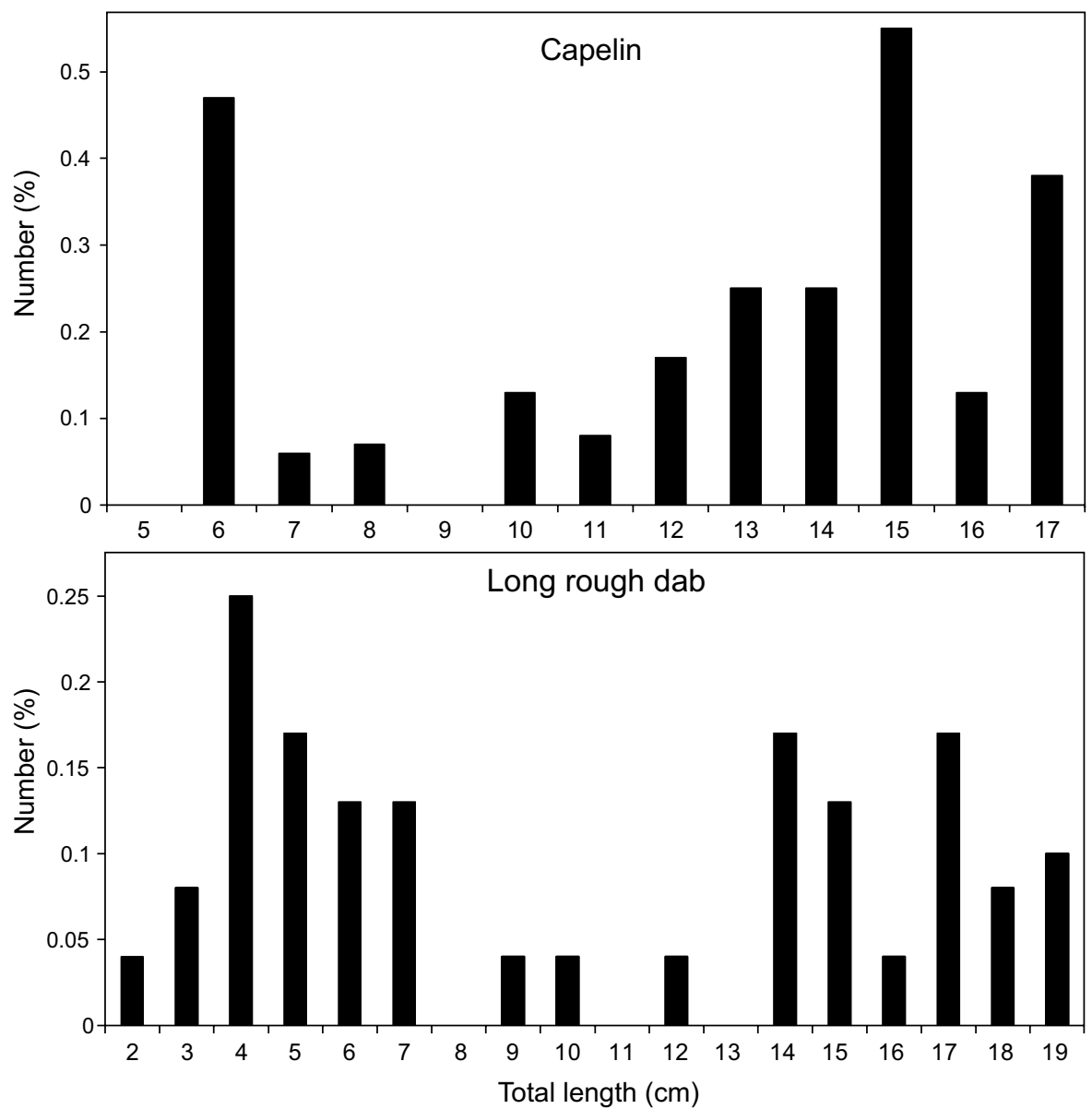

Fig. 7. Length distributions of capelin and long rough dab in the stomachs of thorny skate.

TABLE 2. Estimated food consumption ('000 tons) by thorny skate during 1994-2000. Estimates are based on assumptions of constant annual biomass of skates and constant daily food consumption of $0.8 \%$ of body mass by skates during $1994-2000$.

\begin{tabular}{lrrrrrr}
\hline \hline & \multicolumn{5}{c}{ Year } & \\
\cline { 2 - 6 } Food organisms & $1994-96^{1}$ & 1997 & 1998 & 1999 & 2000 & Mean \\
\hline Euphausiids & 1.8 & 1.7 & 0.9 & 0.5 & 1.1 & 1.2 \\
Hyperiids & 0.0 & 0.0 & 0.0 & 0.0 & 0.1 & 0.0 \\
Commercial species & & & & & & \\
$\quad$ Shrimp & 12.3 & 10.4 & 28.6 & 40.7 & 67.1 & 31.8 \\
$\quad$ Herring & 0.3 & 0.1 & 0.3 & 1.9 & 0.0 & 0.5 \\
Capelin & 3.0 & 6.2 & 21.1 & 40.1 & 0.0 & 14.1 \\
$\quad$ Polar cod & 2.6 & 0.6 & 1.2 & 4.1 & 7.3 & 3.2 \\
Cod & 15.6 & 33.2 & 15.3 & 18.1 & 0.0 & 16.4 \\
$\quad$ Haddock & 1.3 & 0.0 & 0.6 & 2.0 & 0.0 & 0.8 \\
$\quad$ Redfish & 2.6 & 2.0 & 4.9 & 8.2 & 0.0 & 3.5 \\
$\quad$ Long rough dab & 4.7 & 5.6 & 2.4 & 2.0 & 2.0 & 3.4 \\
Other fish & 12.0 & 15.3 & 3.4 & 4.8 & 30.3 & 13.2 \\
Other food & 109.5 & 90.5 & 87.1 & 43.2 & 57.8 & 77.6 \\
Total & 165.7 & 165.7 & 165.7 & 165.7 & 165.7 & 165.7 \\
\hline
\end{tabular}

${ }^{1}$ Data for 1994-96 were combined because of the small sample size and seasonal covering for separate years. 
TABLE 3. Estimated food consumption ('000 tons) by skate species other than thorny skate. Estimates are based on assumptions of constant annual biomass of skates and constant daily food consumption of $1 \%$ of biomass by skates during 1998-2000.

\begin{tabular}{lccccr}
\hline \hline & \multicolumn{5}{c}{ Skate species } \\
\cline { 2 - 5 } Food organisms & Round skate & Arctic skate & Blue skate & Spinytail skate & Total \\
\hline Shrimp & 1.4 & 1.1 & 0.3 & 0.1 & 2.9 \\
Herring & & 2.6 & & & 2.6 \\
Capelin & 0.2 & 2.6 & 1.4 & & 2.8 \\
Cod & 0.1 & & 1.5 & 0.4 & 1.5 \\
Haddock & & 1.0 & 3.6 & 1.5 & 1.9 \\
Redfish & & & 0.3 & & 0.1 \\
Long rough dab & 3.5 & 5.4 & 4.1 & 0.2 & 13.2 \\
Other food & 5.2 & 12.7 & 11.3 & 2.2 & 31.4 \\
Total & & & & & \\
\hline
\end{tabular}

Sail ray is not included because of the small sample size.

\section{References}

ANON. 2002a. Report of the Northern Pelagic and Blue Whiting Fisheries Working Group. ICES C.M. Doc., No. 2002/ ACFM:19, 289 p. 2002b. Report of the Arctic Fisheries Working Group. ICES C.M. Doc., 2002, ACFM:18, 529 p.

ANDRIYASHEV, A. P. 1954. Fishes of the arctic seas of the USSR. Guide to identification of USSR fauna of the Zool. Inst. of the USSR Acad. Sc. Moscow-Leningrad, Acad. Sc. Press, No. 53, 566 p. (in Russian).

ANTIPOVA, T. V., and T. B.NIKIFOROVA. MS 1983. Some data on the nutrition of the thorny skate Raja radiata Donovan in the Barents Sea. ICES C.M. Doc., No. G:22, 17 p.

BERESTOVSKY, E. G. 1989. Feeding of skates Raja radiata Donovan and Raja fyllae Lutken (Rajidae) in the Barents and Norwegian seas. In: Voprosy ihtiologii. V. 29, 6: 994-1002 (in Russian).

BJELLAND, O., O. A. BERGSTAD, J. E. SKJÆRAASEN, and K. MELAND. 2000. Trophic ecology of deep-water fishes associated with the continental slope of the eastern Norwegian Sea. Sarsia, 85: 101-117.

DOLGOV, A. V. MS 1997. Distribution, abundance, biomass and feeding of thorny skate (Raja radiata) in the Barents Sea. ICES C.M. Doc., No. GG:04, 21 p.

1999. Feeding and trophic relations of the Barents Sea cod in the 1980-90s. Abstract of the Ph.D. thesis. Murmansk, 24 p. (in Russian).

MS 2000a. New data on composition and distribution of the Barents Sea ichthyofauna. ICES C.M. Doc., No. 2000, Mini: 12: 13 p.

MS 2000b. Feeding and food consumption by the
Barents Sea predatory fishes in 1980-90s. ICES C.M. Doc., No. 2000, Q:02, 17 p.

DOLGOV, A. V., K. V. DREVETNYAK, and E. V. GUSEV. 2004a. Status of skate stocks in the Barents Sea. In: Symposium on Elasmobranch: Managing for Sustainable Use and Biodiversity Conservation, 11-13 September 2002. J. Northw. Atl. Fish. Sci., 35: 249-260 (this volume).

DOLGOV, A. V., K. M. SOKOLOV, I. P. SHESTOPAL, and A. A.GREKOV. 2004b. By-catch of skates in trawl and long-line fisheries in the Barents Sea. Symposium on Elasmobranch: Managing for Sustainable Use and Biodiversity Conservation, 11-13 September 2002. J. Northw. Atl. Fish. Sci. 35: 357-366 (this volume).

PEDERSEN, S. A. 1995. Feeding habits of starry skate (Raja radiata) in West Greenland waters. ICES J. Mar. Sci., 52: 43-53.

SKJÆRAASEN, J. E., and O. A. BERGSTAD. 2000. Distribution and feeding ecology of Raja radiata in the northeastern North Sea and Skagerrak (Norwegian Deep). ICES J. Mar. Sci., 57: 1249-1260.

STEHMANN, M., and D. L. BÜRKEL. 1984. Rajidae. In: Fishes of the north-eastern Atlantic and Mediterranean. P. J. P.Whitehead, M.-L. Bauchot, J.-C. Hureau, J. Nielsen and E. Tortonese (eds.). UNESCO, Paris. Vol. 1, p. 163-196.

TEMPLEMAN, W. 1982. Stomach contents of the thorny skate, Raja radiata, from the Northwest Atlantic. J. Northw. Atl. Fish. Sci., 3: 123-126.

ZENKEVICH, L. A., and V. A. BROTSKAYA. 1931. Materials on feeding of the Barents Sea fishes. In: Reports of the $1^{\text {st }}$ Session of GOIN, No. 4, p. 1-35 (in Russian). 
